\title{
Chronic and intra-amygdala administrations of the ACTH(4-9) analog ORG 2766 modulate behavioral changes after manipulation of NMDA-receptor activity
}

\author{
I.M.S. van Rijzingen, W.H. Gispen, R. Dam, B.M. Spruijt * \\ Rudolf Magnus Institute for Neurosciences, Universiteitsweg 100, 3584 CG Utrecht, The Netherlands
}

Accepted 30 January 1996

\begin{abstract}
Microinjection of $N$-methyl-D-aspartic acid (NMDA, $300 \mathrm{ng} / 3 \mu \mathrm{l}$ ) into the left lateral ventricle causes a substantial increase in locomotor activity which can be significantly reduced by a chronic pretreatment with the ACTH(4-9) analogue ORG 2766 ( $1 \mu \mathrm{g} / 0.5 \mathrm{ml}$ saline, subcutaneous (s.c.) every day for 7 days, last injection $24 \mathrm{~h}$ before the NMDA-injection). A single dose of ORG 2766 ( $1 \mathrm{ng} / 1 \mu \mathrm{l}$ ) injected into the left central amygdaloid nucleus $30 \mathrm{~min}$ before the NMDA-injection was equally effective in reducing the increase in locomotion. Furthermore it counteracted the predominance of contralateral turning induced by the NMDA-injection. The data give support for the idea that ORG 2766 excerts its effects on behavior and neural recovery by modulating NMDA receptor activity in the brain.
\end{abstract}

Keywords: ORG 2766; Locomotion; Amygdala; Behavior; Hyperactivity

Fragments and analogs of the adrenocorticotrophic hormone $(\mathrm{ACTH})$ can influence behavior of rats and humans $[3,5]$ and enhance functional recovery after damage to the central and peripheral nervous system [14,18]. Chronic administration of the ACTH(4-9) analog ORG 2766 affects the behavior of brain lesioned and aged rats. The peptides efficacy has been supposed to depend on an acceleration of spontaneous recovery through a neurotrophic influence involving some paradigms on functional recovery after peripheral or central nerve damage [7,18], while in studies on the acute effect of ORG 2766 on behavior [5], in various clinical studies [3] and in some brain damage studies $[14,23,24]$ the peptides efficacy was interpreted as an enhancement of (non-selective) attention. Recently a relation between these neurotrophic and attentional effects was suggested [17], when a hypothesis was put forward that both peptide effects were caused by a modulation of NMDA-receptor activity.

Acute subcutaneous administration of ORG 2766 counteracted the impairment in Morris maze performance caused by i.c.v. administration of the NMDA-receptor antagonist

\footnotetext{
${ }^{*}$ Corresponding author. Fax: (31) (30) 2539032.
}

AP5 (D,L-2-amino-5-phosphopentanoic acid), and suppressed the explosive running behavior in an open field induced by i.c.v. administration of NMDA. Although there is one study which indicates that $\mathrm{ACTH}(4-10)$ binds to the NMDA receptor [20], ORG 2766 itself does not affect behavior in the open field and the Morris maze; this suggests that the peptide itself cannot activate this receptor, but rather has an indirect effect.

In studies on isolation-induced disturbances in social behavior, it appeared that the amygdala may be the site of action of the peptide: administration of ORG 2766 into the amygdala was seen to have an effect comparable to subcutaneous administration $[9,22]$. The aim of the present study was threefold:

1. In the previous study it was assumed that chronic treatment with ORG 2766 had a similar effect to acute treatment, and subsequently ORG 2766 was administered acutely. To verify this assumption we investigated whether chronic pre-treatment could also suppress the NMDA-induced locomotor behavior.

2. The possibility that the amygdala is involved in the peptide effects was assessed by examining the effect off ORG 2766 administration into the central nucleus of the amygdala on the NMDA-induced increase in locomotor activity. 
3. In previous experiments it was noticed that animals injected with NMDA mostly circled contralateral in the open field. To elucidate this effect of NMDA, the direction of movement was measured.

Male Wistar rats (approx. $250 \mathrm{~g}$ ) were housed individually under a reversed day-night cycle (lights off at 8.00 , lights on at 20.00) in a humidity- and temperature- $(21 \pm$ $2^{\circ} \mathrm{C}$ ) controlled room. Behavioral tests were performed during the dark period under low red light conditions. Three hours prior to the onset of the experiments animals were brought to the experimental room, which was similar to the rooms used for housing. Food and water were provided at libitum. Surgery: under anesthesia (Hypnorm $0.1 \mathrm{ml} / 100 \mathrm{~g}$, subcutanous - s.c.) cannulas were placed intra-cerebro-ventricularly (i.c.v.) into the left lateral ventricle and animals were allowed 1 week to recover before administration of the peptide began. In Expt. 2, animals also received a cannula in the left central amygdaloid nucleus (after [9] coordinates in position to Bregma: anterior $3.5 \mathrm{~mm}$, lateral, $-4.0 \mathrm{~mm}$, depth, $8.0 \mathrm{~mm}$ ). NMDA ( $N$-methyl-D-aspartate, Sigma) was dissolved in a Trisbuffer $\mathrm{pH} 7.2$, and administered into the ventricle in a dose of $300 \mathrm{ng} / 3 \mu \mathrm{l}$ ), control animals received $3 \mu \mathrm{l}$ of Trisbuffer. In Expt. 1, half the animals received a subcutaneous injection of ORG $2766(1 \mu \mathrm{g} / 0.5 \mathrm{ml}$ saline every day for 7 days prior to NMDA injection), the other animals received $0.5 \mathrm{ml}$ saline on the same schedule.

The last injection was given on the day before the NMDA-injection and testing in an open field. Group sizes were: saline-Tris $n=11$, ORG 2766-Tris $n=9$, salineNMDA $n=14$, ORG 2766-NMDA $n=16$. In Expt. 2, half the animals received one injection of ORG 2766 (1 $\mathrm{ng} / \mathrm{l} \mu \mathrm{l})$ in the amygdala $30 \mathrm{~min}$ before the NMDA-injection and open field testing. Group sizes were saline-Tris $n=12$, ORG 2766-Tris $n=5$, saline-NMDA $n=20$, ORG 2766-NMDA $n=16$. The field consisted of a circular arena ( $140 \mathrm{~cm}$ diameter; $50 \mathrm{~cm}$ high), placed in a soundproof box in the room where the animals were kept, made of dark polyester material with a metal object of $15 \times 15$ $\times 15 \mathrm{~cm}$ in the center, illuminated by dim white light. A video computer system (ETHOVISION, Noldus Information Technology, Wageningen, the Netherlands) was used to measure the distance walked and the direction of each movement (angle) during a period of $10 \mathrm{~min}$. The angle consists of the sum of all angles between two vectors drawn between three positions of the rat, each one second apart. Ipsilateral angles received a positive value, contralateral angles a negative one. Normal rats turn ipsilateral as much as contralateral, subsequently their total angle approximates zero. A significant positive or negative angle indicates predominance of ipsilateral-turning or contralateral-turning, respectively.

When NMDA was injected into the ventricle it resulted in a significant increase in locomotion (the increase amounted to approximately $80 \mathrm{~m}$ ) (assessed by a two-way Analysis of Variance (ANOVA), NMDA effect $F_{1,46}=$

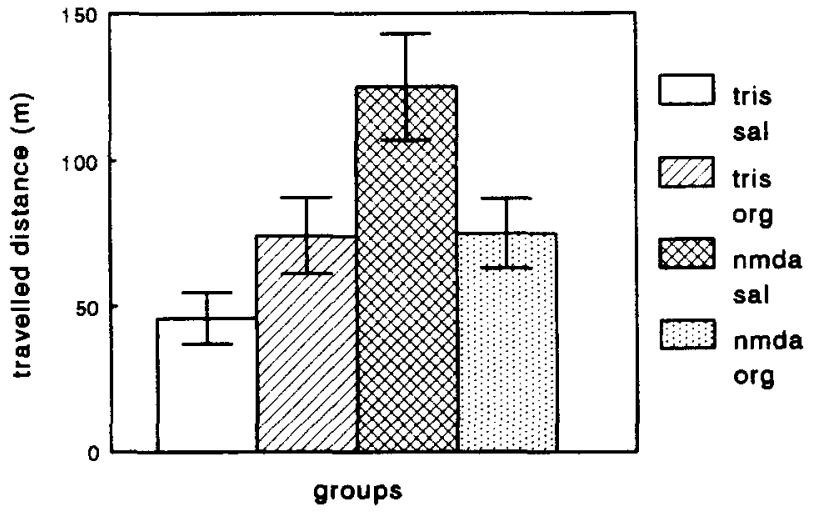

Fig. 1. Mean travelled distance (in $\mathrm{m}$ ) \pm S.E.M. for each group in the open field. Tris $=$ injected i.c.v. with $3 \mu \mathrm{l}$ Tris immediately before testing. NMDA $=$ injected i.c.v. with 300 ng NMDA immediately before testing. $\mathrm{ORG}=$ injected s.c. with $\mathrm{ORG} 2766$ for 7 days prior to testing. sal $=$ injected s.c. with saline for 7 days prior to testing.

7.542, $P<0.01)$. However, this increase in locomotion was not present when animals that received an NMDA injection into the ventricle were pretreated with ORG 2766 for 7 days (2-way ANOVA interaction effect NMDA-ORG $F_{1,46}=7.147, P<0.01$ ) (see Fig. 1). ORG 2766 injections alone (given to Tris-injected animals) did not significantly affect the travelled distance. In Expt. 2 the intraventricular injection of NMDA increased the locomotor activity in the open field. Since the data were not normally distributed (as calculated by the Bartlett test) the $P$-value was calculated by the non-parametric Mann-Whitney $U$ test; MWU saline-Tris vs. saline-NMDA $=53.0 \quad P<0.05)$. NMDAtreated animals had a significant negative (contralateral) total angle, which was assessed with a one-way ANOVA, group differences $F_{3,49}=8.658, P<0.001$ (since group 2 was too small to allow a two-way ANOVA) followed by a Tukey HSD test to test differences between groups, saline-Tris vs. saline-NMDA $P<0.001$. A single injection of ORG 2766 into the amygdala reduced the distance travelled (saline-NMDA vs. ORG-NMDA MWU $=56.0$, $P<0.013)$ and the predominance of contralateral turning (saline-NMDA vs. ORG-NMDA Tukey $P<0.01$ ). Injections of ORG 2766 given to animals that received Tris induced no significant differences in either distance travelled or the angle of movement. The travelled distance is depicted in Fig. 2. In Fig. 3 the total angle of movement is depicted. 0 indicates no preferred direction of movement.

Locomotor hyperactivity induced by unilateral injection of NMDA into the ventricle was reduced by chronic administration of the ACTH(4-9) analog ORG 2766 for 7 days prior to the NMDA injection. Thus the effect of chronic treatment was similar to the effect of acute treatment shown in an earlier study [17]. This yields further evidence for the hypothesis that a modulation of NMDAreceptor activity underlies both the acute effects of ORG 2766 on behavior in rats and humans, and the chronic effects on functional recovery after nerve damage. 


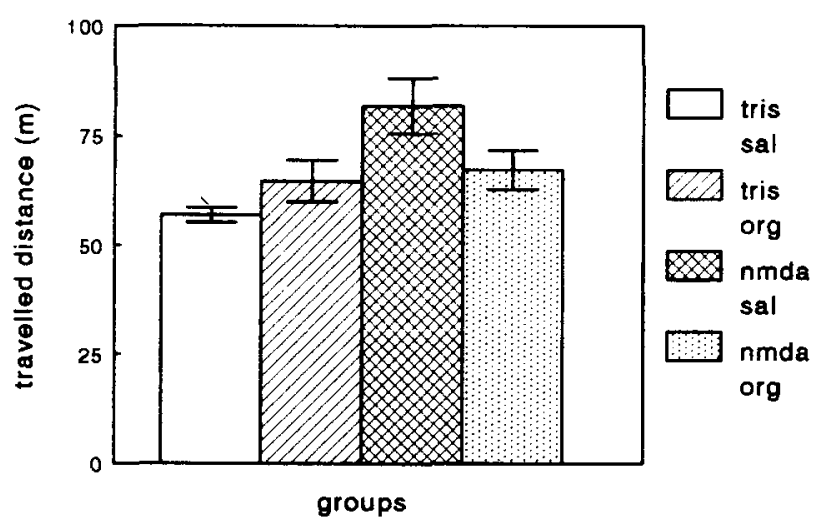

Fig. 2. Mean travelled distance (in $m$ ) \pm S.E.M. for each group in the open field. Tris $=$ injected i.c. $v$. with $3 \mu \mathrm{l}$ Tris immediately before testing. NMDA = injected i.c.v. with $300 \mathrm{ng}$ NMDA immediately before testing. ORG = injected locally in the amygdala with ORG2766 $30 \mathrm{~min}$ prior to testing. $\mathrm{sal}=$ injected locally in the amygdala with saline $30 \mathrm{~min}$ prior to testing.

When the peptide was injected locally into the central nucleus of the amygdala, it also reduced the NMDA-induced locomotor hyperactivity. Furthermore it was seen that i.c.v. administration of NMDA-induced left-turning in the open field; this effect was likewise counteracted by administration of ORG 2766.

It appears that the central nucleus of the amygdala is a site of action for the peptide in the present paradigm. This is in accordance with studies on isolation-induced disturbances in social behavior and locomotory behavior, where intra-amygdala administration of ORG 2766 was equally effective as subcutaneous treatment [9,22]. The central nucleus of the amygdala (CEA) is involved in learning and memory $[11,16]$. The role of the CEA during the acquisition of conditioning tasks is supposed to be an enhancement of the processing of the conditioned stimulus; which is an attentional system [6]. Holland and Gallagher have

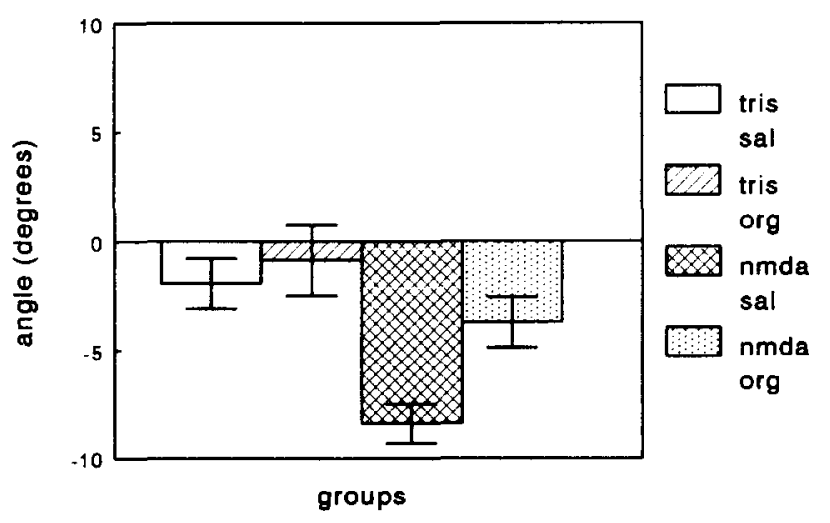

Fig. 3. Mean angle of movement (in degrees) \pm S.E.M. for each group in the open field. Tris $=$ injected i.c.v. with $3 \mu \mathrm{l}$ Tris immediately before testing. NMDA = injected i.c.v. with $300 \mathrm{ng}$ NMDA immediately before testing. ORG = injected locally in the amygdala with ORG2766 (1 ng $\backslash 1$ $\mu 1) 30 \mathrm{~min}$ prior to testing. sal = injected locally in the amygdala with saline $30 \mathrm{~min}$ prior to testing found that the CEA is involved in increasing attention to significant events, but not in tuning out redundant cues [10]. Thus, the idea that the central amygdala is the site of action of ORG 2766 seems in agreement with an effect of the peptide on non-selective attention, which has been suggested after some lesion studies in rats and after studies on human subjects [3].

In the present study ORG 2766 had an effect on excessive locomotor activity after NMDA-receptor activation. In order to understand the nature of the peptide effect it is necessary to understand how the excessive locomotion is generated. Regulation of locomotion is supposed to rely on glutamatergic neurons in the accumbens; injections of NMDA into the nucleus accumbens induce excessive locomotor activity $[2,8]$ as well as intraventricular injections, while intra-accumbal administration of AP5 causes ipsilateral turning [19], which is reminiscent of the effect of NMDA in the present study.

Biochemical and neuroanatomical studies reveal that both the amygdala and the hippocampus have a strong excitatory input into the nucleus accumbens $[12,13]$ and that these projections are glutamatergic [21]. The glutamatergic neurons projecting to the nucleus accumbens are presumably those involved in the regulation of locomotion with the accumbens acting as a link between limbic and motor structures in that it translates signals from the limbic structures into behavioral responses [15].

Both the amygdala and the hippocampus react to environmental challenges, and their afferents to the accumbens are partially overlapping. Cools et al. [4] have proposed that the ventral striatum (which contains the accumbens) acts as a switch between hippocampal and amygdaloid input. The accumbal "seesaw" is either tilted towards opening the gate to hippocampal input, while closing the amygdaloid gate, or tilted the other way with the amygdaloid gate open and the hippocampal gate closed.

An effect of the peptide on tilting the seesaw into the first state; favoring amygdaloid control of behavior over hippocampal control might explain the peptide effect in the present study. It may be that the excessive locomotion relies on hippocampal input into the accumbens, since NMDA injected directly into the hippocampus produces excessive locomotion as well as intraventricular injections (unpublished information). Thus, closing the hippocampal gate would presumably abolish the excessive locomotion.

Moreover, this notion is in agreement with the peptide effect found in an earlier study on damage to the fimbria. In this study the peptide diminished the impairment in Morris maze performance resulting from a fimbria lesion [24], but the peptide was not supposed to enhance recovery of hippocampal function. Rather it was supposed to enhance the attention of the animals to their environment, which improved the performance in the test. This may also be explained by the seesaw effect: the peptide could have favored the use of the amygdala (which we have argued may enhance attention) in solving the problem of the task, 
while closing down the gate which contained the hippocampal input.

One problem in this interpretation needs to be discussed: the present study indicates that ORG 2766 has an effect when injected into the central nucleus of the amygdala, and it is argued that its effect on behavior may be mediated by the seesaw in the accumbens. However, the accumbens receives its main input from the basolateral nucleus of the amygdala, the projections from the central nucleus are small [1]. Perhaps this small projection is significant in influencing behavior. It is also possible that the central and basolateral nuclei work together; since the basolateral nucleus projects to the central nucleus and (though smaller) vice versa [1]. This needs to be further elucidated.

The present results indicate that ORG 2766 can influence NMDA-induced excessive locomotion, probably via the amygdala as the site of action. In this discussion the tentative hypothesis is put forward that the effects of ORG 2766 may be explained by a favoring of the opening of the amygdaloid gate in the accumbens. Further studies will need to be conducted to elucidate if this mechanism may be the basis of the described effects of the peptide.

\section{References}

[1] Amaral, D.G., Price, J.L., Pitkanen, A. and Carmichael, S.T., Anatomical organization of the primate amygdaloid complex. In JP Aggleton (Ed.), The Amygdala: Neurobiological Aspects of Emotion, Memory and Mental Dysfunction, Wiley-Liss, New York, 1992, pp. $1-66$.

[2] Arnt, J., Hyperactivity following injection of a glutamate agonist and 6,7-ADTN into rat nucleus accumbens and its inhibition by THIP, Life Sci., 28 (1981) 1597-1603.

[3] Born, J., Fehm, H.L. and Voigt, K.H., ACTH and attention in humans: a review, Neuropsychobiology, 15 (1986) 165-186.

[4] Cools, A.R., Ploeger, G.E. and Ellenbroek, B.A., Gating function of noradrenaline in the ventral striatum: its role in behavioral responses to environmental and pharmacological challenges. In P. Willner and J. Scheel-Kruger (Eds.), The Mesolimbic Dopamine System: From Motivation to Action, John Wiley and Sons, Chicester, 1991, pp. 141-173.

[5] de Wied, D. and Jolles, J., Neuropeptides derived from pro-opiocortin: behavioral, physiological and neurochemical effects, Physiol. Rev., 62 (1982) 976-1059.

[6] Gallagher, M. and Holland, P.C., Understanding the function of the central nucleus: is simple conditioning enough? In J.P. Aggleton (Ed.), The Amygdala: Neurobiological Aspects of Emotion, Memory and Mental Dysfunction, Wiley-Liss, New York, 1992, pp. 307-321.

[7] Gispen, W.H., Therapeutic potential for melanocortins in peripheral nerve disease, Trends Pharmacol. Sci., 11 (1990) 221-222.

[8] Hamilton, M.H., De Belleroche, J.S., Gardiner, I.M. and Hergerg, L.J., Stimulatory effect on N-methyl aspartate on locomotor activity and transmitter release from rat nucleus accumbens, Pharmacol. Biochem. Behav., 25 (1986) 943-948.

[9] Hol, T. and Spruijt, B.M., The MSH/ACTH(4-9) analog Org 2766 counteracts isolation-induced enhanced social behavior via the anygdala, Peptides, 13 (1992) 541-544.

[10] Holland, P.C. and Gallagher, M., Effects of amygdala central nucleus lesions on blocking and unblocking, Behav. Neurosci., 107 (1993) 235-245.

[11] Izquierdo, I. and Medina, J.H., Role of the amygdala, hippocampus and entorhinal cortex in memory consolidation and expression, Braz. J. Med. Biol. Res., 26 (1993) 573-589.

[12] Kelley, A.E. and Domesick, V.B., The distribution of the projection from the hippocampal formation to the nucleus accumbens in the rat: an antrograde and retrograde horseradish peroxidase study, Neuroscience, 7 (1982) 2321-2335.

[13] Kelley, A.E., Domesick, V.B. and Nauta, W.J.H., The amygdalostriatal projection in the rat - an anatomical study by anterograde and retrograde tracing methods, Neuroscience, 7 (1982) 615-630.

[14] McDaniel, W.F., The influences of fragments and analogs of ACTH/MSH upon recovery from nervous system injury, Behav. Brain Res., 56 (1993) 11-22.

[15] Nauta, W.H.J., Smith, G.P., Faull, R.L. and Domesick, V.B., Efferent connections and nigral afferents of the nucleus accumbens septi in the rat, Neuroscience, 3 (1978) 385-401.

[16] Sarter, M. and Markowitsch, H.J., Involvement of the amygdala in learning and memory; a critical review with emphasis on anatomical relations, Behav. Neurosci., 99 (1985) 342-380.

[17] Spruijt, B.M., Josephy, M., Van Rijzingen, I. and Maaswinkel, H., The ACTH(4-9) analog ORG 2766 modulates the behavioral changes induced by NMDA and the NMDA receptor antagonist AP5, J. Neurosci., 14 (1994) 3225-3230.

[18] Strand, F.L., Lee, S.J., Lee, T.S., Zuccarelli, L.A., Antonawich, F.J., Kume, J. and Williams, K.A., Non-corticotropic ACTH peptides modulate nerve development and regeneration, Rev. Neurosci, 4 (1993) 321-363.

[19] Svensson, A., Carlsson, M.L. and Carlsson, A., Glutamatergic neurons projecting to the nucleus accumbens can affect motor funcions in opposite directions depending on the dopaminergic tone, Prog. Neuro-Psychopharmacol. Biol. Psychiat., 18 (1994) 1203-1218.

[20] Trifiletti, R.R. and Pranzatelli, M.R., ACTH binds to $\langle$ H-3 $\rangle$ MK801-labelled rat hippocampal NMDA receptors, Eur. J. Pharmacol. Mol. Pharm., 226 (1992) 377-379.

[21] Walaas, I., Biochemical evidence for overlapping neocortical and allocortical glutamate projections to the nucleus accumbens and rostral caudatoputamen in the rat brain, Neuroscience, 6 (1981) 399-606.

[22] Wolterink, G. and Van Ree, J.M., Functional recovery after destruction of dopamine systems in the nucleus accumbens of rats. III. Further analysis of the facilitating effect of the ACTH(4-9) analog ORG 2766, Brain Res., 507 (1990) 109-114.

[23] Van Rijzingen, I.M.S., Gispen, W.H. and Spruijt, B.M., Olfactory bulbectomy temporarily impairs Morris maze performance; an ACTH(4-9) analog accelerates return of function, Physiol. Behav., 58 (1995) 147-152.

[24] Van Rijzingen, I.M.S., van Dooremalen, E., Jospchy, M., Gispen, W.H. and Spruijt, B.M., ACTH(4-9) analog Org2766 treatment 7 months delayed still improves Morris maze performance of fimbra fornix lesioned rats, Pharmacol. Biochem. Behav., 53 (1996) 163169. 